\title{
Original Article \\ Comparison of Fitness of Skeletal Muscles in School Children of Urban and Rural Population
}

\author{
Authors \\ Dr Umakant Satapathy ${ }^{1}$, Dr Niharika Panda ${ }^{2}$, Dr. Sulata Mohapatra ${ }^{3}$ \\ ${ }^{1}$ Associate Professor Physiology, Joint Director, Medical Education \&Training, Odisha, India \\ ${ }^{2}$ Associate Professor, Department of Radiotherapy, AHRCC, Cuttack, Odisha \\ ${ }^{3}$ Associate Professor, Department of Physiology, VIMSAR, Burla, Odisha \\ Email: drsulatamohapatra@gmail.com Mob No. +919437167990 \\ Corresponding Author \\ Dr. Niharika Panda \\ N-3/462, IRC Village, Nayapalli, Bhubaneswar, Odisha, India 751015 \\ Email: uksatapathy@yahoo.co.uk Mobile Number:91-9437410842
}

\begin{abstract}
Muscular fitness is one of the important parameter for assessing the physical fitness. Poor physical fitness attributes to different diseases like diabetes mellitus, hypertension, coronary artery disease and different cancers. The present study is aimed to determine the minimum muscular fitness of urban and rural school children by comparing the strength as well as flexibility of muscle. Two hundred school going boys (100 from urban and 100 from rural population) of age 11-14 years were taken for study. Kraus Weber test which is one of the best methods to assess the minimal fitness of a skeletal muscle is employed for assessment of muscle strength and flexibility. It is observed that rural group had more minimum muscle strength as compared to urban (rural $96 \%$ urban $88 \%$ ) and also more flexibility (rural $88 \%$ urban $76 \%$ ). The probable cause could be the sedentary life style in urban population due to advanced modernisation e.g. more TV, laptops and smart phones giving more pleasure rather than the outdoor games in school going boys. A further study taking a larger group can throw more light on the scenario of muscle strength and flexibility in rural and urban populations.
\end{abstract}

Keywords- Muscle Strength, Flexibility, Kraus-Weber test, Physical fitness, Rural \& Urban school going children

\section{Introduction}

Muscular fitness is one of the important parameter for assessing the physical fitness. Poor physical fitness attributes to different diseases like diabetes mellitus, hypertension, coronary artery disease and different cancers. The different disorders of the vital systems like the respiratory system and the cardiovascular system as well as the other systems of human body can be prevented or controlled by maintaining a good physical fitness. Apart from the prevention of disorders of systems it also provides a level of mental wellbeing, emotionally balanced and less stressed conditions. The most common way of testing the fitness of a muscle is to test the strength of the muscle. Kraus Weber test is one of the best methods to assess the minimal fitness of a skeletal muscle. Muscular strength refers to the 
muscles capability to generate force against any resistance and flexibility refers to the capability to perform action around a joint. The aim of the present study is to determine the minimum muscular fitness of urban and rural school children by comparing the strength as well as flexibility of muscle.

\section{Materials \& Methods}

The present study is conducted taking 100 male students studying in an urban school and another 100 students studying in a rural school in the age group of 11 to 14 years. The students suffering from any physical disability, any acute or chronic disease, under any treatment and the students pursuing heavy physical activity and athletes were excluded from study. The physical parameters like age, height weight were recorded. BMI (Body Mass Index) was estimated by Dubois normogram. Clinical examination was done to find the exclusion criteria's. The Kraus- Weber test was demonstrated to all students before performing for record. The students were asked to perform the six tests of the Krause-Weber test. Test-I - The student lies supine and hands are placed behind neck. The examiner while holding the feet asks the student to roll up to sitting position (for Abdominal $\&$ Psoas muscles). Test-II - The student lies supine and hands are placed behind neck with knees bent. The examiner while holding the feet asks the student to roll up to sitting position (for abdominal muscle). Test-III- The student lies supine and hands are placed behind neck with legs extended. The examiner asks the student to raise feet $25 \mathrm{cms}$ above ground and maintains for 10 seconds (for lower abdominal muscles). Test-IV - The student lies prone and keeps a pillow under abdomen nearly at centre of body to have a fulcrum effect. The hands are placed behind neck. The examiner while holding the feet down asks to raise up head, shoulder and chest and maintain for 10 seconds (for upper back muscles). Test-V - The student lies prone and keeps a pillow under abdomen nearly at centre of body to have a fulcrum effect. The hands are placed in front and keeps the head on the hand.
The examiner while holding the chest down asks to raise legs without bending knees, and maintain for 10 seconds (for lower back muscles). Test - VI The student stands erect with hands on his side and feet together. The examiner asks to bend down and touch the floor with fingers but without bending at knees and maintains for 10 seconds (for flexibility of back and hamstring muscles). The steps I to $\mathrm{V}$ of the Kraus-Weber test indicate the strength of the muscles where as the step VI indicates the flexibility around the joints. The observation was recorded as success or failure to perform the test. Statistical analysis was done by using the student's t-test and chi Square test by using the Microsoft Excel.

\section{Results}

The comparison of age, height, weight and the BMI are placed in Table No.1.

Table No 1 Comparison of age, height, weight and the BMI.

\begin{tabular}{|c|c|c|c|}
\hline Parameters & Urban (100) & Rural (100) & $\begin{array}{c}\text { P } \\
\text { value }\end{array}$ \\
\hline $\begin{array}{c}\text { Age } \\
\text { (Completed years) }\end{array}$ & & & \\
11 & 25 & 25 & \\
12 & 25 & 25 & \\
13 & 25 & 25 & \\
14 & 25 & 25 & \\
Mean Height & $142.78 \pm 8.82$ & $140.52 \pm 11.61$ & $>0.05$ \\
Mean Weight & $42.62 \pm 11.23$ & $31.85 \pm 8.92$ & $<0.05$ \\
BMI & $20.95 \pm 4.31$ & $14.98 \pm 2.42$ & $<0.05$ \\
& & & \\
\hline
\end{tabular}

The result of different steps of Kraus-Weber test are shown in Table No. 2

Table. No 2 Comparison of result of different steps of the Kraus-Weber test for strength and flexibility.

\begin{tabular}{|c|c|c|c|c|c|}
\hline Steps & \multicolumn{2}{|c|}{ Urban } & \multicolumn{2}{c|}{ Rural } & P value \\
\hline & Success & Failure & Success & Failure & \\
\hline I & $92(92 \%)$ & $8(8 \%)$ & $94(94 \%)$ & $6(6 \%)$ & $>0.05$ \\
II & $86(86 \%)$ & $14(14 \%)$ & $93(93 \%)$ & $7(7 \%)$ & $>0.05$ \\
III & $84(84 \%)$ & $16(16 \%)$ & $98(98 \%)$ & $2(2 \%)$ & $<0.05^{*}$ \\
IV & $94(94 \%)$ & $6(6 \%)$ & $98(98 \%)$ & $2(2 \%)$ & $>0.05$ \\
V & $84(84 \%)$ & $16(16 \%)$ & $97(97 \%)$ & $3(3 \%)$ & $<0.05^{*}$ \\
VI & $76(76 \%)$ & $24(24 \%)$ & $88(88 \%)$ & $12(12 \%)$ & $<0.05^{*}$ \\
\hline
\end{tabular}


The comparison of overall strength and flexibility in terms of success in performing test or failure to perform a test is shown in Fig. 1.

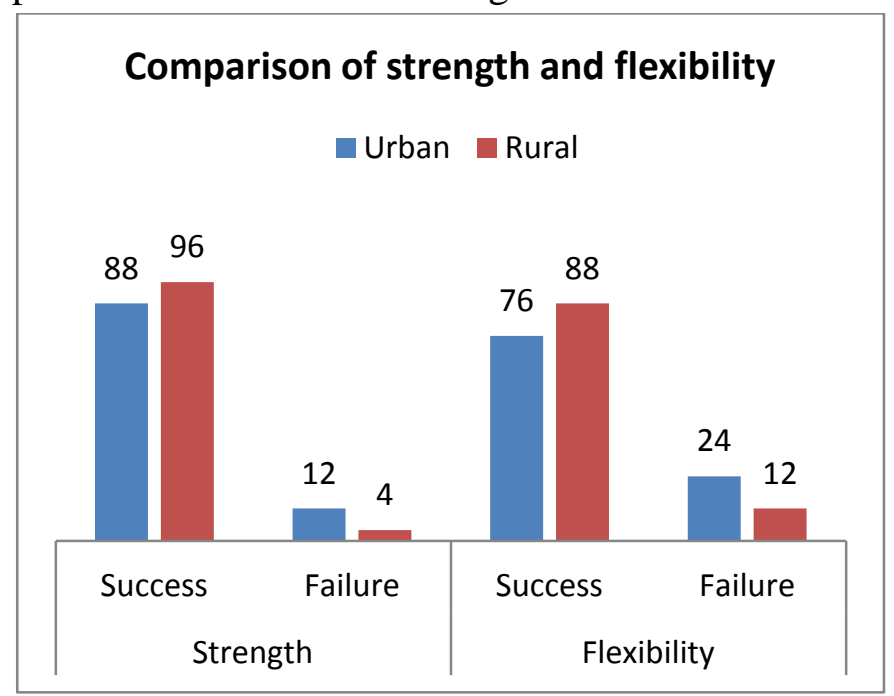

Fig No.1 Comparison of overall strength and flexibility

Table No 3 Comparison of overall muscular fitness.

\begin{tabular}{|c|c|c|c|}
\hline & Urban (100) & Rural (100) & P value \\
\hline Success & $86 \%$ & $94.67 \%$ & $<0.05$ \\
Failure & $14 \%$ & $5.33 \%$ & $<0.05$ \\
\hline
\end{tabular}

\section{Discussion}

The present study is conducted to ascertain the minimum muscular fitness in school going children of age 11 to 14 . Singh et al., $2008^{1}$ quoted that physical fitness is an indicator of several components like endurance, flexibility, speed, strength, agility, body composition etc. A physically fit person looks better, feels better, and thinks better and so lives better. Similar studies are also conducted by Ishtiaq A Bhatt et $\mathrm{al}^{2}$, Kulkarni SD et $\mathrm{al}^{3}$ and Sambhu Prasad ${ }^{4}$. The age height and weight of the present study are similar to the above groups. In urban population $88 \%$ had minimum strength of muscles where as in rural population $96 \%$ had minimum muscle strength $(\mathrm{p}>0.05)$. Similarly $76 \%$ of urban group and $88 \%$ of rural group passed the Kraus-Weber step VI test $(\mathrm{p}<0.05)$ showing the flexibility strength. Though in individual tests of strength the rural group had more success rate the difference from urban group was not significant $(p>0.05)$ but the flexibility in rural group is found to be significantly $(\mathrm{p}<0.05)$ more than urban group. Similar results are also found in other study groups. Gharote and Ganguly ${ }^{5}$ studied on a larger group of 374 school going children and reported a failure in $40.3 \%$. But in his study on 250 children in $2000^{6}$, he observed only $20.8 \%$ failure rate. Babalola et $\mathrm{al}^{7}$ in 2008 studied on 200 school children and observed a failure in $48 \%$ of cases. Ishtiaq et al in 2013 had a study on 250 children and reported a $35.8 \%$ failure rate where as Kulkarni et al in 2010 observed a failure rate of $28.75 \%$. Kraus $\mathrm{H}$ et al in $1953^{8}$ \& $1954^{9}$ compared the muscle fitness between American and European children and observed a failure in test in $56.6 \%$ of American children. It is evident from the earlier and present study that the failure rate in different steps of Kraus- Weber test is in an increasing trend. This may be attributable to the increased sedentary habits with increased mental activity but less physical activity. One of the reasons of such activity is due to more advancement in information technology leading to more use of computers, smart phones and deriving maximum pleasure from them as compared to outdoor games which has led to decreased physical fitness.

\section{Conclusion}

Kraus-Weber test is a very simple and cheapest method to screen a community regarding the general muscle fitness. Muscle fitness as well as flexibility is seen more in rural school going male children in comparison to urban. The causative factors for such varied performance is seen is mostly due to difference in life style mostly in the recreation activities which is mostly outdoor type in rural population contrary to indulge in predominantly indoor type of games or physical activities in urban population. Early detection of less muscle strength and flexibility by such screening methods can prevent a predisposition to various organic and metabolic diseases even including cancers by advising proper and timely physical activity. Further study involving a larger group can throw more light in the scenario of muscle fitness and flexibility in school children. 
No source of support or grant, declared.

No conflict of interest, declared.

\section{References}

1. Singh A, Bains J, Gill J.S. and Brar RS. Essentials of physical education. Kalyani Publishers, 2008; pp.278-282.

2. Ishtiaq Ahmad Bhat, Sakeena Bashir. Comparative study of minimal muscular fitness among rural and urban students of Kashmir. Internat. J. Phy Edu 2013;6(2): 91-94

3. Kulkarni SD, Desai HR, Sharma CS and Bhat PJ. Assessment of muscular fitness in school children using Kraus-Weber tests. Nat J of Integrated Res and Med. 2010; 1 (4) : 30-35.

4. Sambhu Prasad. A survey of minimum muscular strength on school children in Pune district. Int. J of Movement Education and Social Science. 2013; 2(2):60-62.

5. Gharote, ML, Ganguly SK. A survey of minimum muscular fitness of school children. Indian J. Med. Res. 1975; 63 (9):1242-1250.

6. Gharote, ML. Minimum muscular fitness in school children. Indian J Physio \& Pharmacol. 2000; 44(4): 479-484.

7. Babola JF, Awolola OE et al. Reliability of Kraus-Weber exercise test as an evaluation tool in low back pain susceptibility among apparently healthy university students. African $\mathrm{J}$ for Phy Health Edu Recreation and Dance 2008; 14(2): 188-198.

8. Kraus, $H$ and Hirschland RP Muscular fitness tests and health. J. Health Physical Edu. \& Recreation. 1953; 24 (10) :17-19.

9. Kraus, $H$ and Hirschland R. Minimum muscular fitness of the school children. Res. Quarterly. 1954; 25: 178-188. 